\title{
Supervised Clustering Based on DPClusO: Prediction of Plant-Disease Relations Using Jamu Formulas of KNApSAcK Database
}

\author{
Sony Hartono Wijaya, ${ }^{1,2}$ Husnawati Husnawati, ${ }^{3}$ Farit Mochamad Afendi, ${ }^{4}$ \\ Irmanida Batubara, ${ }^{5}$ Latifah K. Darusman, ${ }^{5}$ Md. Altaf-Ul-Amin, ${ }^{1}$ Tetsuo Sato, ${ }^{1}$ \\ Naoaki Ono, ${ }^{1}$ Tadao Sugiura, ${ }^{1}$ and Shigehiko Kanaya ${ }^{1}$ \\ ${ }^{1}$ Graduate School of Information Science, Nara Institute of Science and Technology, 8916-5 Takayama, Ikoma, Nara 630-0192, Japan \\ ${ }^{2}$ Department of Computer Science, Bogor Agricultural University, Kampus IPB Dramaga, Jl. Meranti, Bogor 16680, Indonesia \\ ${ }^{3}$ Department of Biochemistry, Bogor Agricultural University, Kampus IPB Dramaga, Jl. Meranti, Bogor 16680, Indonesia \\ ${ }^{4}$ Department of Statistics, Bogor Agricultural University, Kampus IPB Dramaga, Jl. Meranti, Bogor 16680, Indonesia \\ ${ }^{5}$ Biopharmaca Research Center, Bogor Agricultural University, Kampus IPB Taman Kencana, Jl. Taman Kencana No. 3, \\ Bogor 16151, Indonesia
}

Correspondence should be addressed to Shigehiko Kanaya; skanaya@gtc.naist.jp

Received 30 November 2013; Accepted 18 February 2014; Published 7 April 2014

Academic Editor: Samuel Kuria Kiboi

\begin{abstract}
Copyright (C) 2014 Sony Hartono Wijaya et al. This is an open access article distributed under the Creative Commons Attribution License, which permits unrestricted use, distribution, and reproduction in any medium, provided the original work is properly cited.

Indonesia has the largest medicinal plant species in the world and these plants are used as Jamu medicines. Jamu medicines are popular traditional medicines from Indonesia and we need to systemize the formulation of Jamu and develop basic scientific principles of Jamu to meet the requirement of Indonesian Healthcare System. We propose a new approach to predict the relation between plant and disease using network analysis and supervised clustering. At the preliminary step, we assigned 3138 Jamu formulas to 116 diseases of International Classification of Diseases (ver. 10) which belong to 18 classes of disease from National Center for Biotechnology Information. The correlation measures between Jamu pairs were determined based on their ingredient similarity. Networks are constructed and analyzed by selecting highly correlated Jamu pairs. Clusters were then generated by using the network clustering algorithm DPClusO. By using matching score of a cluster, the dominant disease and high frequency plant associated to the cluster are determined. The plant to disease relations predicted by our method were evaluated in the context of previously published results and were found to produce around $90 \%$ successful predictions.
\end{abstract}

\section{Introduction}

Big data biology, which is a discipline of data-intensive science, has emerged because of the rapid increasing of data in omics fields such as genomics, transcriptomics, proteomics, and metabolomics as well as in several other fields such as ethnomedicinal survey. The number of medicinal plants is estimated to be 40,000 to 70,000 around the world [1] and many countries utilize these plants as blended herbal medicines, for example, China (traditional Chinese medicine), Japan (Kampo medicine), India (Ayurveda, Siddha, and Unani), and Indonesia (Jamu). Nowadays, the use of traditional medicines is rapidly increasing $[2,3]$. These medicines consist of ingredients made from plants, animals, minerals, or combination of them. The traditional medicines have been used for generations for treatments of diseases or maintaining health of people and the most popular form of traditional medicine is herbal medicine. Blended herbal medicines as well as single herb medicines include a large number of constituent substances which exert effects on human physiology through a variety of biological pathways. The KNApSAcK Family database systems can be used to comprehensively understand the medicinal usage of plants based upon traditional and modern knowledge $[4,5]$. This 
TABLE 1: List of diseases using International Classification of Diseases ver. 10 (class of disease IDs correspond to Table 2).

\begin{tabular}{|c|c|c|}
\hline ID & Disease & $\begin{array}{l}\text { Class of } \\
\text { disease }\end{array}$ \\
\hline 1 & Abdominal pain & 3 \\
\hline 2 & Abdominal pain, diarrhea & 3 \\
\hline 3 & Acne & 16 \\
\hline 4 & Acne, skin problems (cosmetics) & 16 \\
\hline 5 & Amenorrhoea, dysmenorrhea & 6 \\
\hline 6 & Amenorrhoea, irregular menstruation & 6 \\
\hline 7 & Anaemia & 1 \\
\hline 8 & Appendicitis, urinary tract infection, tonsillitis & 3 \\
\hline 9 & Arthralgia & 11 \\
\hline 10 & Arthralgia, arthritis & 11 \\
\hline 11 & Asthma & 15 \\
\hline 12 & Benign prostatic hyperplasia (Bph) & 10 \\
\hline 13 & Breast disorder & 6 \\
\hline 14 & Bromhidrosis & 16 \\
\hline 15 & Bronchitis & 15 \\
\hline 16 & Cancer & 2 \\
\hline 17 & Cancer pain & 2 \\
\hline 18 & Cancer, inflammation & 2 \\
\hline 19 & Colic abdomen, bloating (in infant) & 3 \\
\hline 20 & Common cold & 15 \\
\hline 21 & Common cold, dyspepsia, insect bites & $15,3,16$ \\
\hline 22 & Common cold, influenza & 15 \\
\hline 23 & Cough & 15 \\
\hline 24 & Degenerative disease & 14 \\
\hline 25 & Dermatitis, urticaria, erythema & 16 \\
\hline 26 & Diabetes & 14 \\
\hline 27 & Diabetic gangrene & 16 \\
\hline 28 & Diarrhea & 3 \\
\hline 29 & Diarrhea, abdominal pain & 3 \\
\hline 30 & Diseases of the eye & 5 \\
\hline 31 & Disorders in pregnancy & 6 \\
\hline 32 & Dysmenorrhea & 6 \\
\hline 33 & Dysmenorrhea, irregular menstruation & 6 \\
\hline 34 & Dysmenorrhea, menstrual syndrome & 6 \\
\hline 35 & Dyspepsia & 3 \\
\hline 36 & Dyspnoea & 15 \\
\hline 37 & Dyspnoea, cough, orthopnoea & 15 \\
\hline 38 & Fatigue & 11 \\
\hline 39 & Fatigue, anaemia, loss appetite & 1 \\
\hline 40 & Fatigue, lack of sexual function & 6 \\
\hline 41 & Fatigue, low back pain & 11 \\
\hline 42 & Fatigue, myalgia, arthralgia & 11 \\
\hline 43 & Fatigue, osteoarthritis & 11 \\
\hline 44 & Fertility problem & 6,10 \\
\hline 45 & Fever & 0 \\
\hline
\end{tabular}

TABLE 1: Continued.

\begin{tabular}{|c|c|c|}
\hline ID & Disease & $\begin{array}{l}\text { Class of } \\
\text { disease }\end{array}$ \\
\hline 46 & Gastritis, gastric ulcer & 3 \\
\hline 47 & Haemorrhoids & 1 \\
\hline 48 & Headache & 13 \\
\hline 49 & Heart diseases & 8 \\
\hline 50 & Heartburn & 3,8 \\
\hline 51 & Hepatitis, other diseases of liver & 3 \\
\hline 52 & Hypercholesterolaemia & 14 \\
\hline 53 & Hypertension & 8 \\
\hline 54 & Hypertension, diabetes & 14 \\
\hline 55 & Hypertension, hypercholesterolaemia & 14 \\
\hline 56 & Hyperuricemia & 1 \\
\hline 57 & Immunodefficiency & 9 \\
\hline 58 & Indigestion (K.30) & 3 \\
\hline 59 & Indigestion, lose appetite & 3 \\
\hline 60 & Infertility & 6,10 \\
\hline 61 & $\begin{array}{l}\text { Irregular menstruation, menstruation } \\
\text { syndrome }\end{array}$ & 6 \\
\hline 62 & Kidney diseases & 17 \\
\hline 63 & Lactation problems & 6 \\
\hline 64 & Leukorrhoea (Vaginalis) & 6 \\
\hline 65 & Leukorrhoea (Vaginalis), dysmenorrhoea & 6 \\
\hline 66 & Lose appetite & 3 \\
\hline 67 & Lose appetite, underweight & 14 \\
\hline 68 & Low back pain, myalgia, arthralgia & 11 \\
\hline 69 & Low back pain, myalgia, constipation & 11 \\
\hline 70 & Low back pain, urinary tract infection & 17 \\
\hline 71 & Lung diseases & 15 \\
\hline 72 & Malaise and Fatigue & 11 \\
\hline 73 & Malaise and Fatigue, Constipation & 11 \\
\hline 74 & Malaise and Fatigue, Fertility Problems & 10,11 \\
\hline 75 & Malaise and Fatigue, Low Back Pain & 11 \\
\hline 76 & Malaise and Fatigue, Sexual Dysfunction & $11,6,10$ \\
\hline 77 & $\begin{array}{l}\text { Malaise and Fatigue, Skin Problems } \\
\text { (Cosmetics) }\end{array}$ & 16 \\
\hline 78 & Malaria, anaemia & 1 \\
\hline 79 & Meno-metrorrhagia & 6 \\
\hline 80 & Menopausal syndrome & 6 \\
\hline 81 & $\begin{array}{l}\text { Menopause/menstrual syndrome, leukorrhoea } \\
\text { (vaginalis) }\end{array}$ & 6 \\
\hline 82 & Menstrual syndrome & 6 \\
\hline 83 & Menstrual syndrome, fatigue & 6 \\
\hline 84 & Migraine & 13 \\
\hline 85 & Mood disorder & 18 \\
\hline 86 & Myalgia, arthralgia & 11 \\
\hline 87 & Nausea/vomiting of pregnancy & 6 \\
\hline 88 & Osteoarthritis & 11 \\
\hline 89 & Osteoarthritis, fatigue & 11 \\
\hline
\end{tabular}


TABle 1: Continued.

\begin{tabular}{|c|c|c|}
\hline ID & Disease & $\begin{array}{l}\text { Class of } \\
\text { disease }\end{array}$ \\
\hline 90 & Overweight, obesity & 14 \\
\hline 91 & Paralysis & 13 \\
\hline 92 & Post partum syndrome & 6 \\
\hline 93 & Prevent from overweight & 14 \\
\hline 94 & Respiratory infection due to smoking & 15 \\
\hline 95 & Respiratory tract infection & 15 \\
\hline 96 & Rheumatoid arthritis, gout & 11 \\
\hline 97 & Secondary amenorrhea & 6 \\
\hline 98 & Secondary amenorrhea, irregular menstruation & 6 \\
\hline 99 & Sexual dysfunction, fatigue & 6,10 \\
\hline 100 & Skin diseases & 16 \\
\hline 101 & Skin problems (cosmetics) & 16 \\
\hline 102 & Sleeping and Mood Disorders & 18 \\
\hline 103 & Sleeping disorders & 18 \\
\hline 104 & Stomatitis & 3 \\
\hline 105 & Stomatitis, gingivitis, tonsilitis & 3 \\
\hline 106 & Stone in kidney (N20.0) & 17 \\
\hline 107 & $\begin{array}{l}\text { Stone in kidney (N20.0), urinary bladder stone } \\
(\mathrm{N} 21.0)\end{array}$ & 17 \\
\hline 108 & Tonsilitis & 4 \\
\hline 109 & Tonsilofaringitis & 4 \\
\hline 110 & Toothache & 13 \\
\hline 111 & Typhoid, dyspepsia & 3 \\
\hline 112 & Ulcer of anus and rectum & 3 \\
\hline 113 & Underweight, lose appetite & 3 \\
\hline 114 & Urinary tract infection (urethritis) & 17 \\
\hline 115 & Vaginal discharges & 6 \\
\hline 116 & Vaginal diseases & 6 \\
\hline
\end{tabular}

database has information about the selected herbal ingredients, that is, the formulas of Kampo and Jamu, omics information of plants and humans, and physiological activities in humans. Jamu is generally composed based on the experience of the users for decades or even hundreds of years. However, versatile scientific analyses are needed to support their efficacy and their safety. Attaining this objective is in accordance with the 2010 policy of the Ministry of Health of Indonesian Government about scientification of Jamu. Thus, it is required to systemize the formulations and develop basic scientific principles of Jamu to meet the requirement of Indonesian Healthcare System. Afendi et al. initiated and conducted scientific analysis of Jamu for finding the correlation between plants, Jamu, and their efficacy using statistical methods [6-8]. They used Biplot, partial least squares (PLS), and bootstrapping methods to summarize the data and also focused on prediction of Jamu formulations. These methods give a good understanding about relationship between plants, Jamu, and their efficacy. Among 465 plants used in 3138 Jamu, 190 plants were shown to be effective for at least one efficacy and these plants were considered to be the main ingredients of Jamu. The other 275 plants are considered to be supporting ingredients in Jamu because their efficacy has not been established yet.

Network biology can be defined as the study of the network representations of molecular interactions, both to analyze such networks and to use them as a tool to make biological predictions [9]. This study includes modelling, analysis, and visualizations, which holds important task in life science today [10]. Network analysis has been increasingly utilized in interpreting high throughput data on omics information, including transcriptional regulatory networks [11], coexpression networks [12], and protein-protein interactions [13]. We can easily describe relationship between entities in the network and also concentrate on part of the network consisting of important nodes or edges. These advantages can be adopted for analyzing medicinal usage of plants in Jamu and diseases. Network analysis provides information about groups of Jamu that are closely related to each other in terms of ingredient similarity and thus allows precise investigation to relate plants to diseases. On the other hand, multivariate statistical methods such as PLS can assign plants to efficacy by global linear modeling of the Jamu ingredients and efficacy. However, there is still lack of appropriate network based methods to learn how and why many plants are grouped in certain Jamu formula and the combination rule embedding numerous Jamu formulas.

It is needed to explore the relationship between Indonesian herbal plants used in Jamu medicines and the diseases which are treated using Jamu medicines. When effectiveness of a plant against a disease is firmly established, then further analysis about that plant can be proceeded to molecular level to pinpoint the drug targets. The present study developed a network based approach for prediction of plant-disease relations. We utilized the Jamu data from the KNApSAcK database. A Jamu network was constructed based on the similarity of their ingredients and then Jamu clusters were generated using the network clustering algorithm DPClusO $[14,15]$. Plant-disease relations were then predicted by determining the dominant diseases and plants associated with selected Jamu clusters.

\section{Methods}

2.1. Concept of the Methodology. Jamu medicines consist of combination of medicinal plants and are used to treat versatile diseases. In this work we exploit the ingredient similarity between Jamu medicines to predict plant-disease relations. The concept of the proposed method is depicted in Figure 1. In step 1 a network is constructed where a node is a Jamu medicine and an edge represents high ingredient similarity between the corresponding Jamu pair. In Figure 1, the nodes of the same color indicate the Jamu medicines used for the same disease. The similarity is represented by Pearson correlation coefficient $[16,17]$; that is,

$$
\operatorname{corr}(X, Y)=\frac{\sum_{i=1}^{l}\left(x_{i}-\bar{x}\right)\left(y_{i}-\bar{y}\right)}{\sqrt{\sum_{i=1}^{l}\left(x_{i}-\bar{x}\right)^{2} \sum_{i=1}^{l}\left(y_{i}-\bar{y}\right)^{2}}}
$$


TABLE 2: Distribution of Jamu formulas according to 18 classes of disease (classes of diseases are determined by NCBI in ID1 to ID16 and by the present study in ID17 and ID18 represented by asterisks in Ref. columns).

\begin{tabular}{|c|c|c|c|c|}
\hline ID & Class of disease (NCBI) & Ref. & Number of Jamu & Percentage \\
\hline 1 & Blood and lymph diseases & NCBI & 201 & 6.41 \\
\hline 2 & Cancers & NCBI & 32 & 1.02 \\
\hline 3 & The digestive system & NCBI & 457 & 14.56 \\
\hline 4 & Ear, nose, and throat & NCBI & 2 & 0.06 \\
\hline 5 & Diseases of the eye & $\mathrm{NCBI}$ & 1 & 0.03 \\
\hline 6 & Female-specific diseases & NCBI & 382 & 12.17 \\
\hline 7 & Glands and hormones & NCBI & 0 & - \\
\hline 8 & The heart and blood vessels & NCBI & 57 & 1.82 \\
\hline 9 & Diseases of the immune system & NCBI & 22 & 0.70 \\
\hline 10 & Male-specific diseases & NCBI & 17 & 0.54 \\
\hline 11 & Muscle and bone & NCBI & 649 & 20.68 \\
\hline 12 & Neonatal diseases & NCBI & 0 & - \\
\hline 13 & The nervous system & NCBI & 32 & 1.02 \\
\hline 14 & Nutritional and metabolic diseases & NCBI & 576 & 18.36 \\
\hline 15 & Respiratory diseases & NCBI & 313 & 9.97 \\
\hline 16 & Skin and connective tissue & NCBI & 163 & 5.19 \\
\hline 17 & The urinary system & * & 90 & 2.87 \\
\hline \multirow[t]{4}{*}{18} & Mental and behavioral disorders & * & 21 & 0.67 \\
\hline & The number of Jamu classified into multiple disease classes & & 119 & 3.79 \\
\hline & The number of Jamu unclassified & & 4 & 0.13 \\
\hline & Total Jamu formulas & & 3138 & 100.00 \\
\hline
\end{tabular}

where $x_{i}$ is the weight of plant- $i$ in Jamu $X, y_{i}$ is the weight of plant- $i$ in Jamu $Y, \bar{x}$ is mean of Jamu $X$, and $\bar{y}$ is mean of Jamu $Y$. The higher similarity between Jamu pairs the higher the correlation value. In the present study, $x_{i}$ and $y_{i}$ are assigned as 1 or 0 in cases the $i$ th plant is, respectively, included or not included in the formula. Under such condition, Pearson correlation corresponds to fourfold point correlation coefficient; that is,

$$
\operatorname{corr}(X, Y)=\frac{a d-b c}{\sqrt{(a+b)(a+c)(b+d)(c+d)}},
$$

where $a, b, c$, and $d$ represent the numbers of plants included in both $X$ and $Y$, in only $X$, in only $Y$, and in neither $X$ nor $Y$, respectively.

In step 2 the Jamu clusters are generated using network clustering algorithm DPClusO. DPClusO can generate clusters characterized by high density and identified by periphery; that is, the Jamu medicines belonging to a cluster are highly cohesive and separated by a natural boundary. Such clusters contain potential information about plant-disease relations.

In step 3 we assess disease-dominant clusters based on matching score represented by the following equation:

matching score

$$
=\frac{\text { number of Jamu belonging to the same disease }}{\text { total number of Jamu in the cluster }} \text {. }
$$

Matching score of a cluster is the ratio of the highest number of Jamu associated with a single disease to the total number of Jamu in the cluster. We assign a disease to a cluster for which the matching score is greater than a threshold value. In step 4, we determine the frequency of plants associated with a cluster if and only if a disease is assigned to it in the previous step. The highest frequency plant associated to a cluster is considered to be related to the disease assigned to that cluster. True positive rates (TPR) or sensitivity was used to evaluate resulting plants. TPR is the proportion of the true positive predictions out of all the true predictions, defined by the following formula [18]:

$$
\mathrm{TPR}=\frac{\mathrm{TP}}{\mathrm{TP}+\mathrm{FN}}
$$

where true positive (TP) is the number of correctly classified and false negative (FN) is the number of incorrectly rejected entities. We refer to the proposed method as supervised clustering because after generation of the clusters we narrow down the candidate clusters for further analysis based on supervised learning and thus improve the accuracy of prediction of the proposed method.

\section{Result and Discussion}

3.1. Construction and Comparison of Jamu and Random Networks. We used the same number of Jamu formulas from previous research [6], 3138 Jamu formulas, and the set union 


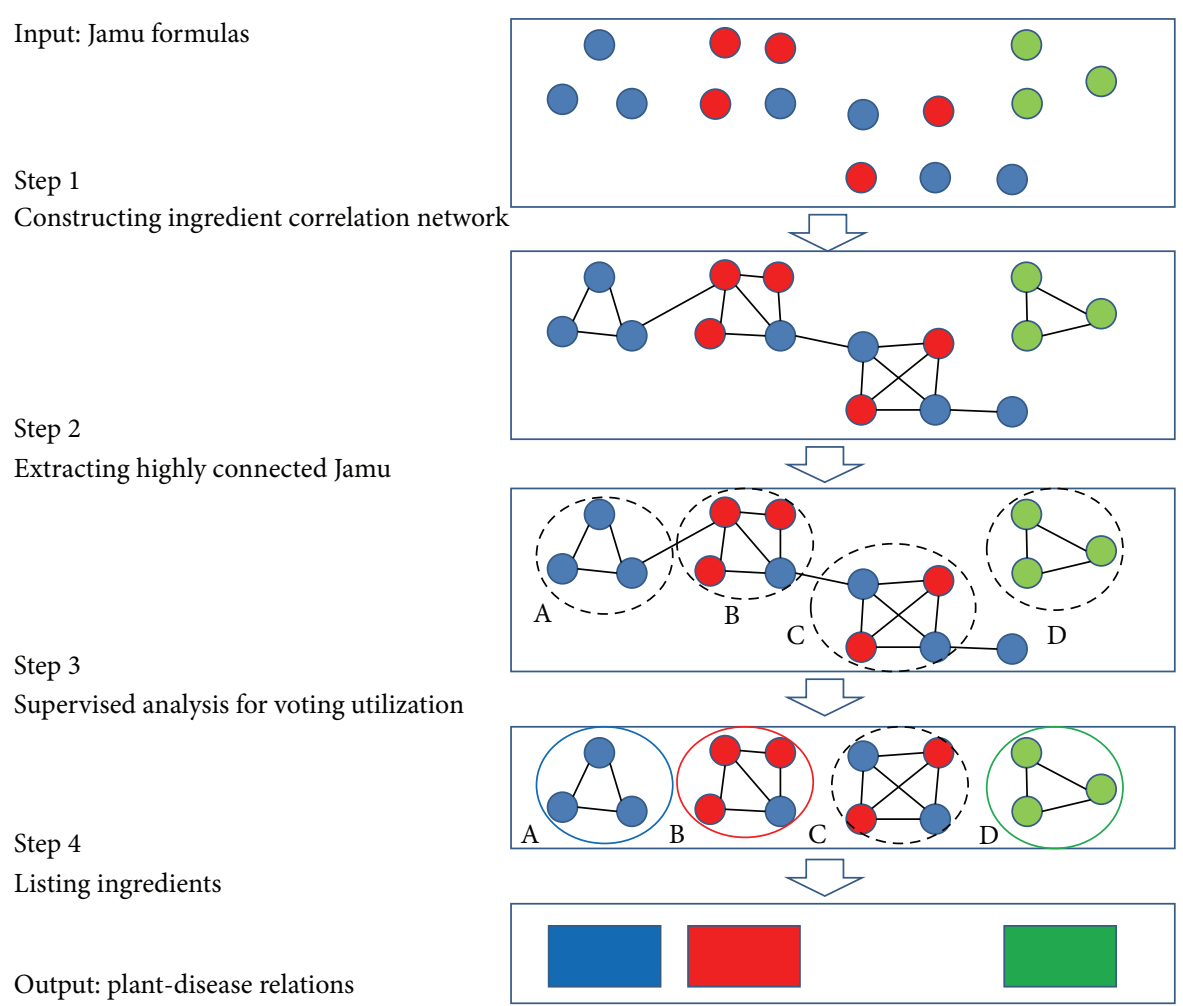

FIGURE 1: Concept of the methodology: network construction based on ingredient similarity between individual Jamu medicines, network clustering, and classification of medicinal plants to dominant disease.

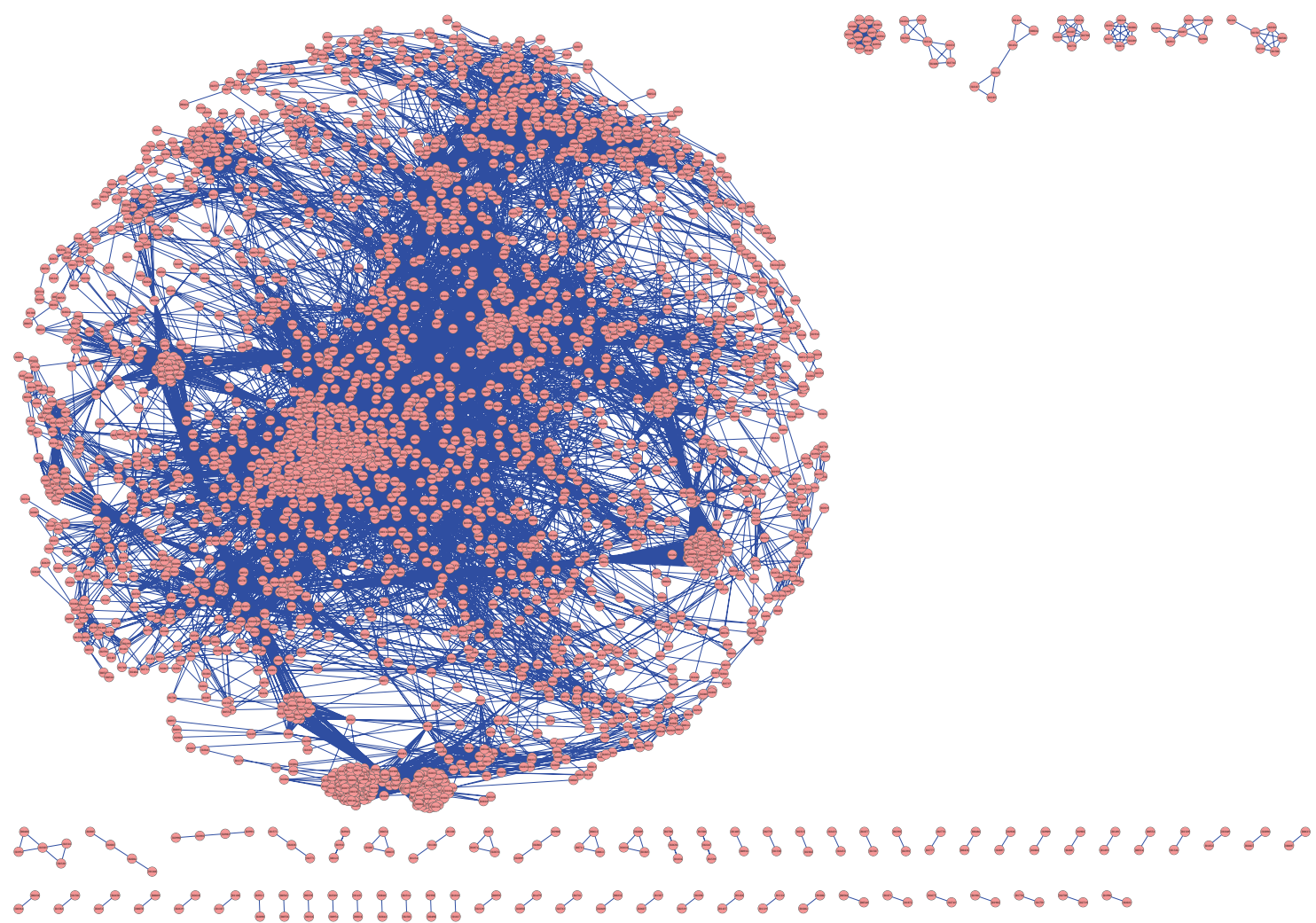

FIGURE 2: The network consisting of $0.7 \%$ Jamu pairs (correlation value above or equal to 0.596 ). 
TABLE 3: Statistics of three datasets.

\begin{tabular}{|c|c|c|c|c|}
\hline & Parameters & $0.7 \%$ & $0.5 \%$ & $0.3 \%$ \\
\hline \multirow{21}{*}{$\begin{array}{l}\text { Network } \\
\text { statistics }\end{array}$} & Total pairs & 34,454 & 24,610 & 14,766 \\
\hline & Minimum correlation & 0.596 & 0.665 & 0.718 \\
\hline & Number of Jamu formulas & 2,779 & 2,496 & 2,085 \\
\hline & Average degree & 24.8 & 19.7 & 14.2 \\
\hline & (Random network: ER) & $(24.8 \pm 0.0)$ & $(19.7 \pm 0.0)$ & $(14.2 \pm 0.0)$ \\
\hline & (Random network: BA) & $(24.7 \pm 0.1)$ & $(19.7 \pm 0.1)$ & $(14.1 \pm 0.1)$ \\
\hline & (Random network: CNN) & $(24.7 \pm 0.4)$ & $(19.7 \pm 0.4)$ & $(14.0 \pm 0.4)$ \\
\hline & Clustering coefficient & 0.521 & 0.520 & 0.540 \\
\hline & (Random network: ER) & $(0.009 \pm 0.000)$ & $(0.008 \pm 0.000)$ & $(0.007 \pm 0.000)$ \\
\hline & (Random network: BA) & $(0.030 \pm 0.001)$ & $(0.028 \pm 0.001)$ & $(0.026 \pm 0.001)$ \\
\hline & (Random network: CNN) & $(0.246 \pm 0.008)$ & $(0.239 \pm 0.008)$ & $(0.233 \pm 0.010)$ \\
\hline & Number of connected components & 69 & 119 & 254 \\
\hline & (Random networks: ER, BA, CNN) & (1) & (1) & (1) \\
\hline & Network diameter & 15 & 17 & 20 \\
\hline & (Random network: ER) & $(4.0 \pm 0.0)$ & $(4.0 \pm 0.0)$ & $(5.0 \pm 0.0)$ \\
\hline & (Random network: BA) & $(10.8 \pm 0.8)$ & $(11.2 \pm 1.5)$ & $(10.8 \pm 0.9)$ \\
\hline & (Random network: CNN) & $(14.6 \pm 1.9)$ & $(14.1 \pm 1.4)$ & $(14.7 \pm 1.3)$ \\
\hline & Network density & 0.008 & 0.008 & 0.007 \\
\hline & (Random network: ER) & $(0.009 \pm 0.000)$ & $(0.008 \pm 0.000)$ & $(0.007 \pm 0.000)$ \\
\hline & (Random network: BA) & $(0.009 \pm 0.000)$ & $(0.008 \pm 0.000)$ & $(0.007 \pm 0.000)$ \\
\hline & (Random network: CNN) & $(0.009 \pm 0.000)$ & $(0.008 \pm 0.000)$ & $(0.007 \pm 0.000)$ \\
\hline \multirow{4}{*}{ DPClusO } & Total number of clusters & 1,746 & 1,411 & 938 \\
\hline & Number of clusters with more than 2 Jamu & 1,296 & 873 & 453 \\
\hline & $(\%)$ & $(74.2)$ & $(61.9)$ & $(48.3)$ \\
\hline & Number of Jamu formulas in the biggest cluster & 118 & 104 & 89 \\
\hline
\end{tabular}

of all formulas consists of 465 plants. We assigned 3138 Jamu formulas to 116 diseases of International Classification of Diseases (ICD) version 10 from World Health Organization (WHO, Table 1) [19]. Those 116 diseases are mapped to 18 classes of disease, which contains 16 classes of disease from National Center for Biotechnology Information (NCBI) [20] and 2 additional classes. Table 2 shows distribution of 3138 Jamu into 18 classes of disease. According to this classification, most Jamu formulas are useful for relieving muscle and bone, nutritional and metabolic diseases, and the digestive system. Furthermore, there is no Jamu formula classified into glands and hormones and neonatal disease classes. We excluded 4 Jamu formulas which are used to treat fever in the evaluation process because this symptom is very general and almost appeared in all disease classes. Jamuplant-disease relations can be represented using 2 matrices: first matrix is Jamu-plant relation with dimension $3138 \times$ 465 and the second matrix is Jamu-disease relation with dimension $3138 \times 18$.

After completion of data acquisition process, we calculated the similarity between Jamu pairs using correlation measure. The similarity measures between Jamu pairs were determined based on their ingredients. Corresponding to $K$ (3138 in present case) Jamu formulas, there can be maximum $(K \times(K-1) / 2)=(3138 \times(3137 / 2))=4,921,953 \mathrm{Jamu}$ pairs. We sorted the Jamu pairs based on correlation value using descending order and selected top- $n(0.7 \%, 0.5 \%$, and $0.3 \%$ ) pairs of Jamu formula to create 3 sets of Jamu pairs. The number of Jamu pairs for $0.7 \%, 0.5 \%$, and $0.3 \%$ datasets is 34,454 pairs, 24,610 pairs, and 14,766 pairs and the corresponding minimum correlation values are 0.596 , 0.665 , and 0.718 , respectively. The three datasets of Jamu pairs can be regarded as three undirected networks (step 1 in Figure 1) consisting of 2779, 2496, and 2085 Jamu formulas, respectively (Table 3 ). Figure 2 shows visualization of $0.7 \%$ Jamu networks using Cytoscape Spring Embedded layout. We verified that the degree distributions of the Jamu networks are somehow close to those of scale-free networks, that is, roughly are of power law type. However, in the high-degree region the power law structure is broken (Figure 3 ). Nearly accurate relation of power laws between medicinal herbs and the number of formulas utilizing them was observed in Jamu system but not in Kampo (Japanese crude drug system) [4]. The difference of formulas between Jamu and Kampo can be explained by herb selection by medicinal researchers based on the optimization process of selection [4]. Thus, the broken structure of power law corresponding to Jamu networks is associated with the fact that selection of Jamu pairs based on ingredient correlation leads to nonrandom selection. We also constructed random networks according 

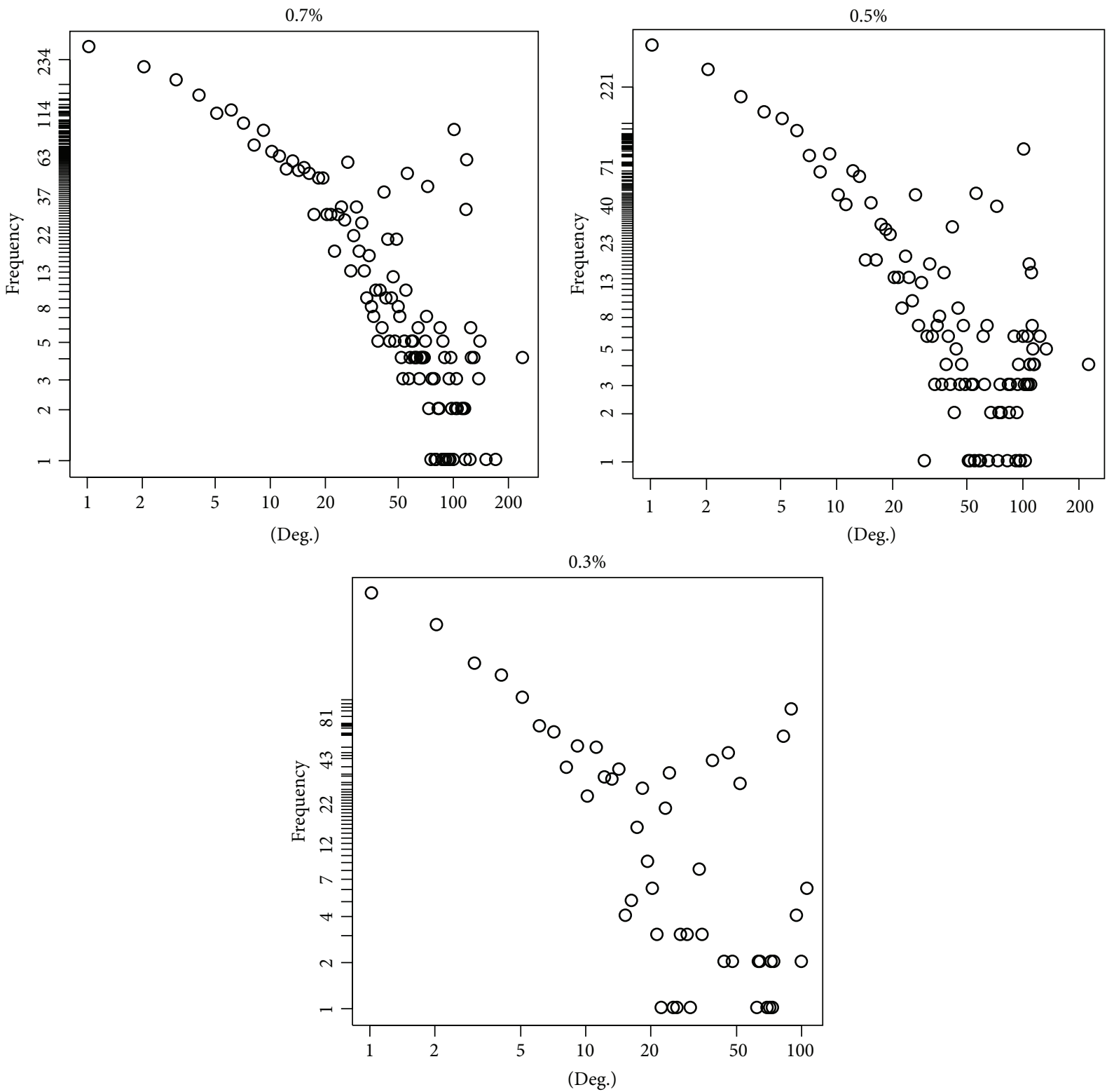

FIGURE 3: Degree distributions of three Jamu networks roughly follow power law. The $x$-axis corresponds to the log of degree of a node in the Jamu network and the $y$-axis corresponds to the log of the number of Jamu.

to Erdős-Rényi (ER) model [21], Barabási-Albert (BA) model [22], and Vazquez's Connecting Nearest Neighbor (CNN) model [23] of the same size corresponding to each of the real Jamu network. We used Cytoscape Network Analyzer plugin [24] and R software for analyzing the characteristics of both the Jamu and the random networks.

We determined five statistical indexes, that is, average degree, clustering coefficient, number of connected component, network diameter, and network density of each Jamu network and also of each random network. The clustering coefficient $C_{n}$ of a node $n$ is defined as $C_{n}=2 e_{n} /\left(k_{n}\left(k_{n}-1\right)\right)$, where $k_{n}$ is the number of neighbors of $n$ and $e_{n}$ is the number of connected pairs between all neighbors of $n$. The network diameter is the largest distance between any two nodes. If a network is disconnected, its diameter is the maximum of all diameters of its connected components. A network's density is the ratio of the number of edges in the network over the total number of possible edges between all pairs of nodes (which is $n(n-1) / 2$, where $n$ is the number of vertices, for an undirected graph). The average number of neighbors and the network density are the same for the real and random networks of the same size as it is shown in Table 3. In case of $0.7 \%$ and $0.5 \%$ real networks, the clustering coefficient is roughly the same and in case of $0.3 \%$ the clustering coefficient is somewhat larger. The number of connected components and the diameter of the Jamu networks gradually decrease as the network grows bigger by addition of more nodes and edges. 


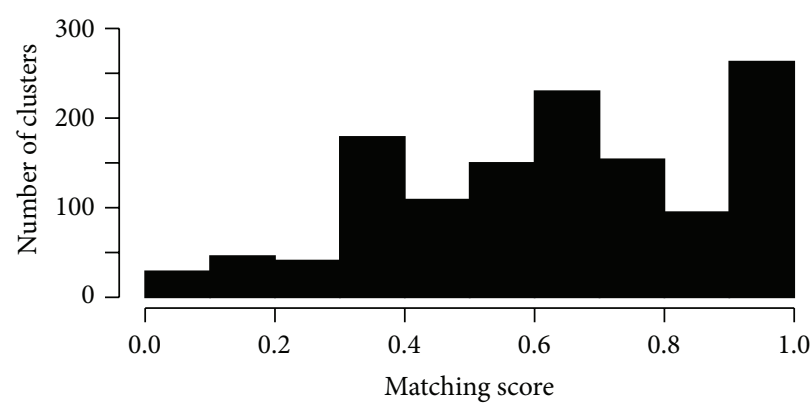

(a) $0.7 \%$

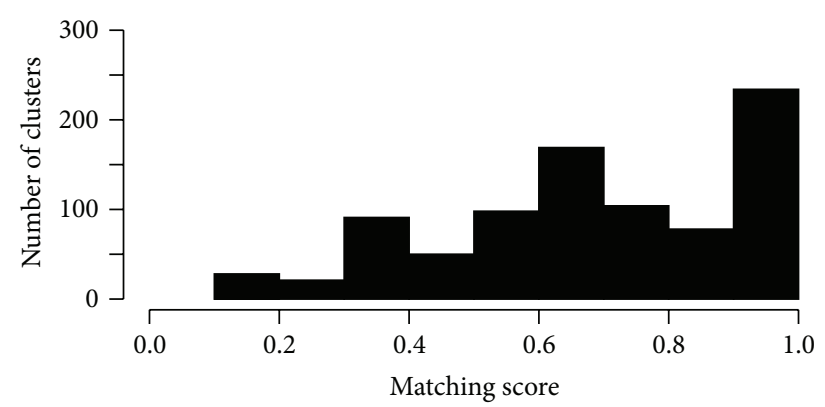

(b) $0.5 \%$

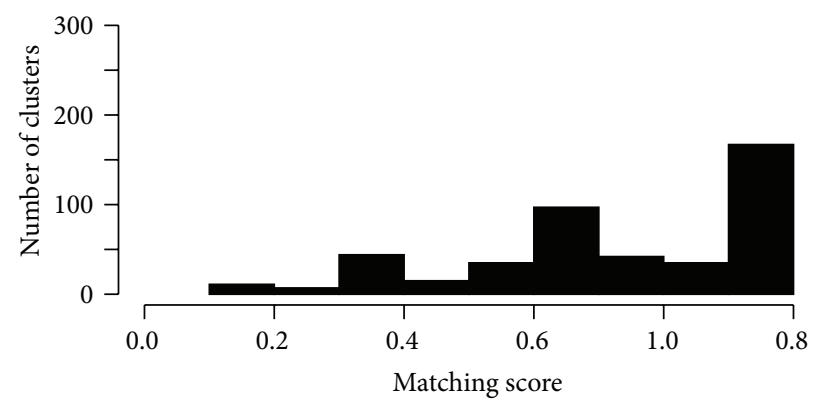

(c) $0.3 \%$

FIGURE 4: Distribution of clusters based on matching score.

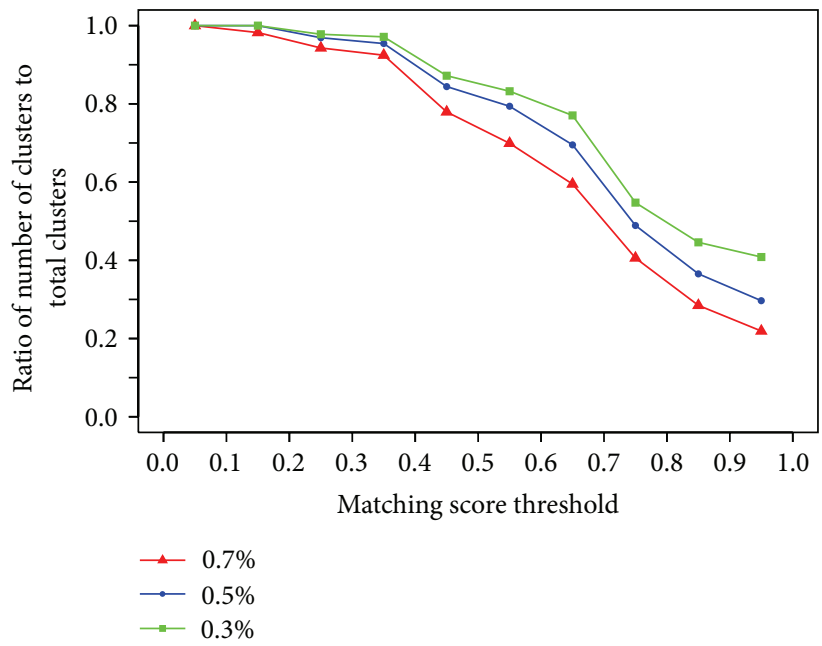

(a)

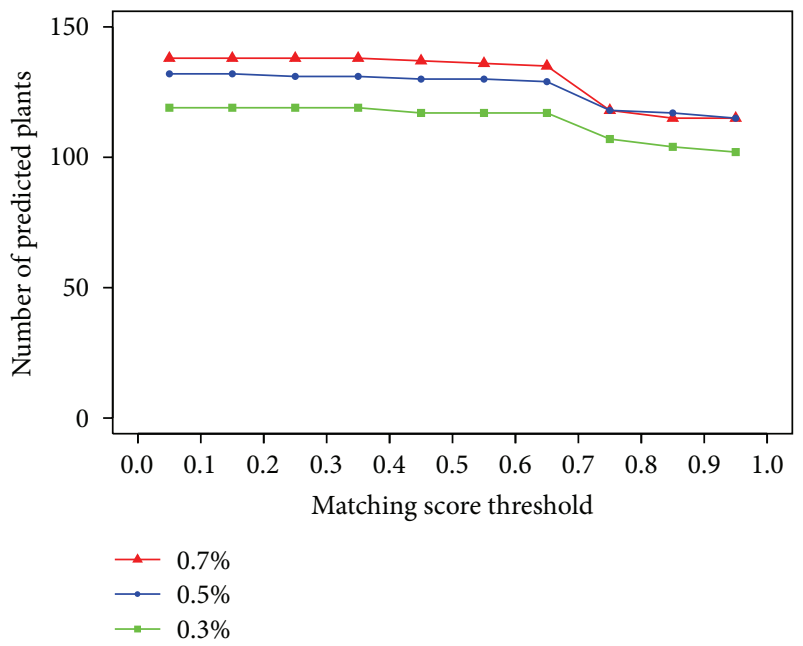

(b)

FIGURE 5: (a) Success rate and (b) number of predicted plants with respect to matching score thresholds.

Very different values corresponding to clustering coefficient, connected component, and network diameter imply that the Jamu networks are quite different from all 3 types of random networks. The differences between Jamu networks and ER random networks are the largest. Random networks constructed based on other two models are also substantially different from Jamu networks. Based on the fact that the random networks constructed based on all three types of models are different from the Jamu networks, it can be concluded that structure of Jamu networks is reasonably biased and thus might contain certain information about plant-disease relations. Specially, much higher value corresponding to clustering coefficient indicates that there are clusters in the networks worthy to be investigated. To extract clusters from the Jamu networks (step 2 in Figure 1) we applied DPClusO network clustering algorithm [14] to generate overlapping clusters based on density and periphery tracking.

3.2. Supervised Clustering Based on DPClusO. DPClusO is a general-purpose clustering algorithm and useful for finding overlapping cohesive groups in an undirected simple graph 
TABLE 4: List of plants assigned to each disease.

\begin{tabular}{|c|c|c|c|}
\hline \multicolumn{2}{|c|}{ Number Plants name } & \multicolumn{2}{|c|}{ Hit-miss status } \\
\hline \multicolumn{4}{|c|}{ A. Disease: blood and lymph diseases } \\
\hline 1 & Tamarindus indica & Hit & * \\
\hline 2 & Allium sativum & Hit & * \\
\hline 3 & Tinospora tuberculata & Hit & * \\
\hline 4 & Piper retrofractum & Hit & \\
\hline 5 & Syzygium aromaticum & Hit & * \\
\hline 6 & Bupleurum falcatum & Hit & \\
\hline 7 & Graptophyllum pictum & Hit & \\
\hline 8 & Plantago major & Hit & \\
\hline 9 & Zingiber officinale & Hit & * \\
\hline 10 & Cinnamomum burmannii & Hit & * \\
\hline 11 & Soya $\max$ & Miss & * \\
\hline 12 & Kaempferia galanga & Hit & \\
\hline 13 & Curcuma longa & Hit & * \\
\hline 14 & Piper nigrum & Hit & \\
\hline 15 & Zingiber aromaticum & Hit & * \\
\hline 16 & Phyllanthus urinaria & Hit & * \\
\hline 17 & Oryza sativa & Hit & \\
\hline 18 & Myristica fragrans & Hit & * \\
\hline 19 & Alstonia scholaris & Hit & * \\
\hline 20 & Syzygium polyanthum & Miss & \\
\hline 21 & Andrographis paniculata & Hit & * \\
\hline 22 & Sida rhombifolia & Miss & \\
\hline 23 & Cyperus rotundus & Hit & \\
\hline 24 & Sonchus arvensis & Miss & \\
\hline 25 & Curcuma aeruginosa & Hit & * \\
\hline \multirow[t]{2}{*}{26} & Curcuma xanthorrhiza & Hit & \\
\hline & B. Disease: cancers & & \\
\hline \multirow[t]{2}{*}{1} & Catharanthus roseus & Hit & \\
\hline & Disease: the digestive syster & & \\
\hline 1 & Foeniculum vulgare & Hit & \\
\hline 2 & Glycyrrhiza uralensis & Hit & * \\
\hline 3 & Imperata cylindrica & Hit & \\
\hline 4 & Zingiber purpureum & Hit & * \\
\hline 5 & Physalis peruviana & Hit & \\
\hline 6 & Punica granatum & Hit & * \\
\hline 7 & Echinacea purpurea & Hit & \\
\hline 8 & Zingiber officinale & Hit & * \\
\hline 9 & Psidium guajava & Hit & \\
\hline 10 & Baeckea frutescens & Hit & * \\
\hline 11 & Amomum compactum & Hit & \\
\hline 12 & Cinnamomum burmannii & Hit & * \\
\hline 13 & Melaleuca leucadendra & Hit & \\
\hline 14 & Caesalpinia sappan & Hit & * \\
\hline 15 & Parkia roxburghii & Hit & \\
\hline 16 & Rheum tanguticum & Hit & \\
\hline 17 & Kaempferia galanga & Hit & \\
\hline 18 & Coriandrum sativum & Hit & \\
\hline
\end{tabular}

TABle 4: Continued.

\begin{tabular}{|c|c|c|c|}
\hline \multirow{2}{*}{$\begin{array}{l}\text { Number } \\
19\end{array}$} & \multirow{2}{*}{$\begin{array}{l}\text { Plants name } \\
\text { Curcuma longa }\end{array}$} & \multicolumn{2}{|c|}{ Hit-miss status } \\
\hline & & Hit & \\
\hline 20 & Zingiber aromaticum & Hit & \\
\hline 21 & Phyllanthus urinaria & Hit & \\
\hline 22 & Myristica fragrans & Hit & \\
\hline 23 & Hydrocotyle asiatica & Hit & $*$ \\
\hline 24 & Carica papaya & Hit & \\
\hline 25 & Mentha arvensis & Hit & \\
\hline 26 & Lepiniopsis ternatensis & Hit & \\
\hline 27 & Helicteres isora & Hit & \\
\hline 28 & Andrographis paniculata & Hit & \\
\hline 29 & Symplocos odoratissima & Hit & \\
\hline 30 & Schisandra chinensis & Hit & \\
\hline 31 & Blumea balsamifera & Hit & \\
\hline 32 & Silybum marianum & Hit & $*$ \\
\hline 33 & Cinnamomum sintoc & Hit & \\
\hline 34 & Elephantopus scaber & Hit & \\
\hline 35 & Curcuma aeruginosa & Hit & \\
\hline 36 & Kaempferia pandurata & Hit & \\
\hline 37 & Curcuma xanthorrhiza & Hit & \\
\hline 38 & Curcuma mangga & Hit & * \\
\hline 39 & Curcuma zedoaria & Hit & \\
\hline 40 & Daucus carota & Hit & $*$ \\
\hline 41 & Matricaria chamomilla & Hit & * \\
\hline 42 & Cymbopogon nardus & Hit & * \\
\hline D. 1 & Disease: female-specific disec & & \\
\hline 1 & Foeniculum vulgare & Hit & \\
\hline 2 & Imperata cylindrica & Hit & \\
\hline 3 & Tamarindus indica & Hit & \\
\hline 4 & Pluchea indica & Hit & * \\
\hline 5 & Piper retrofractum & Hit & \\
\hline 6 & Punica granatum & Hit & \\
\hline 7 & Uncaria rhynchophylla & Hit & \\
\hline 8 & Zingiber officinale & Hit & \\
\hline 9 & Guazuma ulmifolia & Hit & * \\
\hline 10 & Nigella sativa & Hit & \\
\hline 11 & Terminalia bellirica & Hit & \\
\hline 12 & Baeckea frutescens & Hit & \\
\hline 13 & Phaseolus radiatus & Hit & \\
\hline 14 & Amomum compactum & Hit & * \\
\hline 15 & Sauropus androgynus & Hit & \\
\hline 16 & Usnea misaminensis & Hit & \\
\hline 17 & Cinnamomum burmannii & Hit & \\
\hline 18 & Melaleuca leucadendra & Hit & \\
\hline 19 & Parameria laevigata & Hit & \\
\hline 20 & Parkia roxburghii & Hit & \\
\hline 21 & Piper cubeba & Hit & \\
\hline 22 & Kaempferia galanga & Hit & \\
\hline
\end{tabular}


TABLE 4: Continued.

\begin{tabular}{lll}
\hline Number & Plants name & Hit-miss status \\
\hline 23 & Coriandrum sativum & Hit \\
24 & Kaempferia angustifolia & Hit \\
25 & Curcuma longa & Hit \\
26 & Zingiber aromaticum & Hit \\
27 & Languas galanga & Hit \\
28 & Galla lusitania & Hit \\
29 & Quercus lusitanica & Hit \\
30 & Hydrocotyle asiatica & Hit \\
31 & Areca catechu & Hit \\
32 & Lepiniopsis ternatensis & Hit \\
33 & Helicteres isora & Hit \\
34 & Piper betle & Hit \\
35 & Elephantopus scaber & Hit \\
36 & Kaempferia pandurata & Hit \\
37 & Curcuma xanthorrhiza & Hit \\
38 & Sesbania grandiflora & Hit \\
\hline
\end{tabular}

E. Disease: the heart and blood vessels

Allium sativum

Curcuma longa

Morinda citrifolia

Homalomena occulta

Hydrocotyle asiatica

Alstonia scholaris

Syzygium polyanthum

Andrographis paniculata

Apium graveolens

Imperata cylindrica

F. Disease: male-specific diseases

Cucurbita pepo

Serenoa repens

Baeckea frutescens

Phaseolus radiatus

Curcuma longa

Elephantopus scaber

G. Disease: muscle and bone

Foeniculum vulgare

Clausena anisum-olens

Zingiber purpureum

Allium sativum

Strychnos ligustrina

Tinospora tuberculata

Piper retrofractum

Syzygium aromaticum

Cola nitida

Ginkgo biloba

Panax ginseng

Equisetum debile

Zingiber officinale
TABle 4: Continued.

\begin{tabular}{|c|c|c|c|}
\hline Number & Plants name & Hit- 1 & ss status \\
\hline 14 & Ganoderma lucidum & Hit & \\
\hline 15 & Nigella sativa & Hit & \\
\hline 16 & Terminalia bellirica & Hit & * \\
\hline 17 & Baeckea frutescens & Hit & $*$ \\
\hline 18 & Amomum compactum & Hit & \\
\hline 19 & Cinnamomum burmannii & Hit & \\
\hline 20 & Melaleuca leucadendra & Hit & \\
\hline 21 & Parameria laevigata & Hit & * \\
\hline 22 & Psophocarpus tetragonolobus & Hit & * \\
\hline 23 & Parkia roxburghii & Hit & \\
\hline 24 & Piper cubeba & Hit & * \\
\hline 25 & Kaempferia galanga & Hit & \\
\hline 26 & Coriandrum sativum & Hit & \\
\hline 27 & Cola acuminata & Hit & \\
\hline 28 & Coffea arabica & Hit & \\
\hline 29 & Orthosiphon stamineus & Hit & \\
\hline 30 & Curcuma longa & Hit & \\
\hline 31 & Piper nigrum & Hit & \\
\hline 32 & Alpinia galanga & Hit & \\
\hline 33 & Vitex trifolia & Hit & \\
\hline 34 & Zingiber amaricans & Hit & $*$ \\
\hline 35 & Zingiber zerumbet & Hit & \\
\hline 36 & Zingiber aromaticum & Hit & \\
\hline 37 & Languas galanga & Hit & \\
\hline 38 & Massoia aromatica & Hit & \\
\hline 39 & Morinda citrifolia & Hit & \\
\hline 40 & Carum copticum & Hit & * \\
\hline 41 & Panax pseudoginseng & Hit & * \\
\hline 42 & Oryza sativa & Hit & \\
\hline 43 & Myristica fragrans & Hit & \\
\hline 44 & Pandanus amaryllifolius & Hit & \\
\hline 45 & Eurycoma longifolia & Hit & \\
\hline 46 & Hydrocotyle asiatica & Hit & \\
\hline 47 & Areca catechu & Hit & * \\
\hline 48 & Mentha arvensis & Hit & $*$ \\
\hline 49 & Lepiniopsis ternatensis & Hit & \\
\hline 50 & Pimpinella pruatjan & Hit & \\
\hline 51 & Andrographis paniculata & Hit & \\
\hline 52 & Blumea balsamifera & Hit & \\
\hline 53 & Cymbopogon nardus & Hit & \\
\hline 54 & Sida rhombifolia & Hit & \\
\hline 55 & Cinnamomum sintoc & Hit & \\
\hline 56 & Piper betle & Hit & $*$ \\
\hline 57 & Talinum paniculatum & Hit & \\
\hline 58 & Elephantopus scaber & Hit & \\
\hline 59 & Cyperus rotundus & Hit & \\
\hline 60 & Curcuma aeruginosa & Hit & \\
\hline 61 & Kaempferia pandurata & Hit & $*$ \\
\hline
\end{tabular}


TABLE 4: Continued.

\begin{tabular}{lll}
\hline Number & Plants name & Hit-miss status \\
\hline 62 & Curcuma xanthorrhiza & Hit \\
63 & Tribulus terrestris & Hit \\
64 & Corydalis yanhusuo & Hit \\
65 & Pausinystalia yohimbe & Hit \\
\hline
\end{tabular}

H. Disease: nutritional and metabolic diseases

3

4

5

6

7

8

9

10

11

12

13

4

14

Foeniculum vulgare

Hit

Glycyrrhiza uralensis

Zingiber purpureum

Hit

Allium sativum

Tinospora tuberculata

Pandanus conoideus

Syzygium aromaticum

Punica granatum

Zingiber officinale

Guazuma ulmifolia

Nigella sativa

Amomum compactum

Cinnamomum burmannii

Parameria laevigata

Caesalpinia sappan

Soya max

Cocos nucifera

Rheum tanguticum

Piper cubeba

Murraya paniculata

Kaempferia galanga

Coffea arabica

Orthosiphon stamineus

Curcuma longa

Piper nigrum

Zingiber aromaticum

Aloe vera

Phaleria papuana

Galla lusitania

Quercus lusitanica

Morinda citrifolia

Myristica fragrans

Momordica charantia

Areca catechu

Lepiniopsis ternatensis

Alstonia scholaris

Hibiscus sabdariffa

Laminaria japonica

Syzygium polyanthum

Andrographis paniculata

Sindora sumatrana

Cassia angustifolia

Woodfordia floribunda

Hit

Hit

Hit

Hit

Hit

Hit

Hit

Hit

Hit

Hit

Hit

Hit

Hit

Hit

Hit

Hi

Hit

Hit

Hit

Hit

Hit

Hit

Hit

Hit

Hit

Hit

Hit

Hit

Hit

Hit

Hit

Hit

Hit

Hit

Hit

Hit

Hit

Hit

Hit
TABle 4: Continued.

\begin{tabular}{lll}
\hline Number & Plants name & Hit-miss status \\
\hline 44 & Piper betle & Hit \\
45 & Spirulina & Hit \\
46 & Stevia rebaudiana & Hit \\
47 & Theae sinensis & Hit \\
48 & Sonchus arvensis & Hit \\
49 & Curcuma heyneana & Hit \\
50 & Curcuma aeruginosa & Hit \\
51 & Kaempferia pandurata & Hit * \\
52 & Curcuma xanthorrhiza & Hit \\
53 & Curcuma zedoaria & Hit \\
54 & Olea europaea & Hit \\
\hline
\end{tabular}

I. Disease respiratory diseases
Foeniculum vulgare

Hit

Clausena anisum-olens

Hit

Glycyrrhiza uralensis

Hit

Zingiber purpureum

Piper retrofractum

Syzygium aromaticum

Gaultheria punctata

Panax ginseng

Equisetum debile

Zingiber officinale

Citrus aurantium

Nigella sativa

Amomum compactum

Cinnamomum burmannii

Melaleuca leucadendra

Parkia roxburghii

Hit

Hit

Hit

Hit

Hit

Hit

Hit

Hit

Hit

Hit

Hit

$\begin{array}{ll}* & 14 \\ * & 15\end{array}$

16

17

Cocos nucifera

Hit

Piper cubeba

Hit

Kaempferia galanga

Coriandrum sativum

Hit

Curcuma longa Hit

Piper nigrum Hit

Zingiber aromaticum Hit

Languas galanga Hit

Mentha piperita Hit

Oryza sativa

Myristica fragrans

Pandanus amaryllifolius

Hydrocotyle asiatica

Mentha arvensis

Lepiniopsis ternatensis

Helicteres isora

Blumea balsamifera

Cymbopogon nardus

Piper betle

Curcuma xanthorrhiza

\section{(n)}

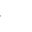

it

t

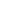

it

it

$*$


TABLE 4: Continued.

\begin{tabular}{|c|c|c|c|}
\hline \multirow{2}{*}{\multicolumn{2}{|c|}{$\begin{array}{ll}\text { Number } & \text { Plants name } \\
37 & \text { Salix alba }\end{array}$}} & \multicolumn{2}{|c|}{ Hit-miss status } \\
\hline & & Hit & * \\
\hline 38 & Matricaria chamomilla & Miss & * \\
\hline \multicolumn{4}{|c|}{ J. Disease: skin and connective tissue } \\
\hline 1 & Strychnos ligustrina & Hit & \\
\hline 2 & Merremia mammosa & Hit & * \\
\hline 3 & Piper retrofractum & Hit & $*$ \\
\hline 4 & Santalum album & Hit & \\
\hline 5 & Zingiber officinale & Hit & $*$ \\
\hline 6 & Citrus aurantium & Hit & \\
\hline 7 & Citrus hystrix & Hit & \\
\hline 8 & Cassia siamea & Hit & \\
\hline 9 & Cocos nucifera & Hit & \\
\hline 10 & Trigonella foenum-graecum & Hit & \\
\hline 11 & Orthosiphon stamineus & Hit & \\
\hline 12 & Curcuma longa & Hit & \\
\hline 13 & Vetiveria zizanioides & Hit & \\
\hline 14 & Aloe vera & Hit & \\
\hline 15 & Rosa chinensis & Hit & \\
\hline 16 & Jasminum sambac & Hit & \\
\hline 17 & Phyllanthus urinaria & Hit & \\
\hline 18 & Mentha piperita & Hit & \\
\hline 19 & Oryza sativa & Hit & \\
\hline 20 & Myristica fragrans & Hit & * \\
\hline 21 & Hydrocotyle asiatica & Hit & \\
\hline 22 & Lepiniopsis ternatensis & Hit & \\
\hline 23 & Alstonia scholaris & Hit & \\
\hline 24 & Andrographis paniculata & Hit & \\
\hline 25 & Cymbopogon nardus & Hit & \\
\hline 26 & Piper betle & Hit & \\
\hline 27 & Theae sinensis & Hit & \\
\hline 28 & Curcuma heyneana & Hit & \\
\hline 29 & Kaempferia pandurata & Hit & * \\
\hline 30 & Curcuma xanthorrhiza & Hit & \\
\hline 31 & Melaleuca leucadendra & Hit & \\
\hline 32 & Matricaria chamomilla & Miss & * \\
\hline \multicolumn{4}{|c|}{ K. Disease: the urinary system } \\
\hline 1 & Foeniculum vulgare & Hit & $*$ \\
\hline 2 & Imperata cylindrica & Hit & $*$ \\
\hline 3 & Strychnos ligustrina & Hit & $*$ \\
\hline 4 & Plantago major & Hit & \\
\hline 5 & Zingiber officinale & Hit & $*$ \\
\hline 6 & Cinnamomum burmannii & Hit & * \\
\hline 7 & Strobilanthes crispus & Hit & \\
\hline 8 & Kaempferia galanga & Hit & * \\
\hline 9 & Orthosiphon stamineus & Hit & \\
\hline 10 & Phyllanthus urinaria & Hit & \\
\hline 11 & Blumea balsamifera & Hit & * \\
\hline 12 & Sonchus arvensis & Hit & \\
\hline 13 & Curcuma xanthorrhiza & Hit & \\
\hline
\end{tabular}

${ }^{*}$ indicates that plant will not assigned if we use matching score $>0.7$.

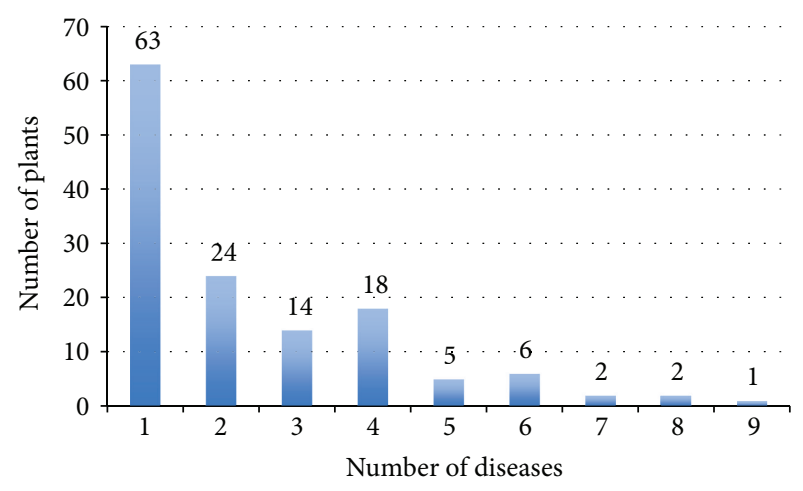

FIGURE 6: Distribution of 135 plants assigned based on $0.7 \%$ dataset with respect to the number of diseases they are assigned to.

for any type of application. It ensures coverage and performs robustly in case of random addition, removal, and rearrangement of edges in protein-protein interaction (PPI) networks [14]. While applying DPClusO, the parameter values of density and cluster property that we used in this experiment are 0.9 and 0.5 , respectively [15]. Table 3 shows the summary of clustering result by DPClusO. Because clusters consisting of two Jamu formulas are trivial clusters, for the next steps we only use clusters each of which consists of 3 or more Jamu formulas. The number of total clusters increases along with the larger dataset, although the threshold correlation between Jamu pairs decreases. We evaluated the clustering result using matching score to determine dominant disease for every cluster (step 3 in Figure 1). Matching score of a cluster is the ratio of the highest number of Jamu associated with the same disease to the total number of Jamu in the cluster. Thus matching score is a measure to indicate how strongly a disease is associated to a cluster. Figure 4 shows the distribution of the clusters with respect to matching score from three datasets. All datasets have the highest frequency of clusters at matching score $>0.9$ and overall most of the clusters have higher matching score, which means most of the DPClusO generated clusters can be confidently related to a dominant disease. Furthermore the number of clusters with matching score $>0.9$ is remarkably larger compared to the same in other ranges of matching score in case of the $0.3 \%$ dataset (Figure 4(c)). If we compare the ratio of frequency of clusters at matching score $>0.9$ for every dataset, the $0.3 \%$ dataset has the highest ratio with 40.84\% (of 453), compared to $29.67 \%$ (of 873 ) and $21.91 \%$ (of 1296 ), in case of $0.5 \%$ and $0.7 \%$ datasets, respectively. Thus, the most reliable species to disease relations can be predicted at matching score $>0.9$ corresponding to the clusters generated from $0.3 \%$ dataset.

Figure 5(a) shows the success rate for all 3 datasets with respect to threshold matching scores. Success rate is defined as the ratio of the number of clusters with matching score larger than the threshold to the total number of clusters. As expected it tends to produce lower success rate if we decrease correlation value to create the datasets. However more clusters are generated and more information can be extracted when we lower the threshold correlation value. The success rate increases rapidly as the matching score decreases 
TABLE 5: Relation between disease classes in NCBI and efficacy classes reported by Afendi et al. [6].

\begin{tabular}{|c|c|c|}
\hline Class of disease & Ref. & Efficacy class \\
\hline D1 Blood and lymph diseases & NCBI & E7 Pain/inflammation (PIN) \\
\hline D2 Cancers & NCBI & E7 Pain/inflammation (PIN) \\
\hline \multirow{2}{*}{ D3 The digestive system } & \multirow{2}{*}{ NCBI } & E4 Gastrointestinal disorders (GST) \\
\hline & & E7 Pain/inflammation (PIN) \\
\hline D4 Ear, nose, and throat & NCBI & E7 Pain/inflammation (PIN) \\
\hline D5 Diseases of the eye & NCBI & E7 Pain/inflammation (PIN) \\
\hline D6 Female-specific diseases & NCBI & E5 Female reproductive organ problems (FML) \\
\hline D7 Glands and hormones & NCBI & E7 Pain/inflammation (PIN) \\
\hline D8 The heart and blood vessels & NCBI & E7 Pain/inflammation (PIN) \\
\hline D9 Diseases of the immune system & NCBI & E7 Pain/inflammation (PIN) \\
\hline D10 Male-specific diseases & NCBI & E6 Musculoskeletal and connective tissue disorders (MSC) \\
\hline D11 Muscle and bone & NCBI & E6 Musculoskeletal and connective tissue disorders (MSC) \\
\hline D12 Neonatal diseases & NCBI & E7 Pain/inflammation (PIN) \\
\hline D13 The nervous system & NCBI & E7 Pain/inflammation (PIN) \\
\hline \multirow{2}{*}{ D14 Nutritional and metabolic diseases } & \multirow{2}{*}{ NCBI } & E2 Disorders of appetite (DOA) \\
\hline & & E4 Gastrointestinal disorders (GST) \\
\hline \multirow{2}{*}{ D15 Respiratory diseases } & \multirow{2}{*}{ NCBI } & E8 Respiratory disease (RSP) \\
\hline & & E7 Pain/inflammation (PIN) \\
\hline D16 Skin and connective tissue & NCBI & E9 Wounds and skin infections (WND) \\
\hline D17 The urinary system & $*$ & E1 Urinary related problems (URI) \\
\hline D18 Mental and behavioural disorders & * & E3 Disorders of mood and behavior (DMB) \\
\hline
\end{tabular}

from 0.9 to 0.6 and after that the slope of increase of success rate decreases. Therefore in this study we empirically decide 0.6 as the threshold matching score to predict plant-disease relations.

3.3. Assignment of Plants to Disease. By using DPClusO resulting clusters, we assigned plants to classes of disease. Based on a threshold matching score we assigned dominant disease to a cluster. Then we assign a plant to a cluster by way of analyzing the ingredients of the Jamu formulas belonging to that cluster and determining the highest frequency plant, that is, the plant that is used for maximum number Jamu belonging to that cluster (step 4 in Figure 1). Thus we assign a disease and a plant to each cluster having matching score greater than a threshold. Our hypothesis is that the disease and the plant assigned to the same cluster are related.

The total number of assigned plants depends on matching score value. Figure 5(b) shows the number of predicted plants that can be assigned to diseases in the context of matching score. With higher matching score value, the number of predicted plants assigned to classes of disease is supposed to remain similar or decrease but the reliability of prediction increases. In Figure 5(b) a sudden change in the number of predicted plants is seen at matching score 0.6 which we consider as empirical threshold in this work. Based on the $0.7 \%$ dataset, the largest number of plants (135 plants, Table 4) was assigned to diseases. There are 63 plants assigned to only one class of disease, whereas the other 72 plants are assigned to at least two or more classes of disease (Figure 6).
3.4. Evaluation of the Supervised Clustering Based on DPClu$s O$. We used previously published results [6] as gold standard to evaluate our results. The previous study assigned plants to 9 kinds of efficacy whereas we assigned the plants to 18 disease classes (16 from NCBI and 2 additional classes). For the sake of evaluation we got done a mapping of the 18 disease classes to 9 efficacy classes by a professional doctor, which is shown in Table 5. Table 6 shows the prediction result of plant-disease relations for all 3 datasets, corresponding to clusters with matching score greater than 0.6. Table 6 also shows corresponding efficacy, the number of assigned plants, number of correctly predicted plants, and true positive rates (TPR), respectively.

We determined TPR corresponding to a disease/efficacy class by calculating the ratio of the number of correct prediction to the number of all predictions. When a disease corresponds to more than one kind of efficacy, the highest TPR can be considered the TPR for the corresponding disease. For all 3 datasets the TPR corresponding to each disease is roughly $90 \%$ or more. The $0.3 \%$ dataset consists of Jamu pairs with higher correlation values and based on this dataset 117 plants are assigned to 14 disease classes. The $0.7 \%$ dataset contains more Jamu pairs and assigned plants to 11 disease classes, one less disease class compared to $0.5 \%$ dataset. The two disease classes covered by $0.3 \%$ dataset but not covered by $0.5 \%$ and $0.7 \%$ datasets are the nervous system (D13) and disease of the immune system (D9). The only disease class covered by $0.3 \%$ and $0.5 \%$ datasets but not covered by $0.7 \%$ dataset is mental and behavioural disorders (D18). The larger dataset network tends to have 
TABLE 6: The prediction result of plant-disease relations using matching score $>0.6$.

\begin{tabular}{|c|c|c|c|c|c|c|c|c|c|c|}
\hline \multirow[b]{2}{*}{$\begin{array}{l}\text { Class of } \\
\text { disease }\end{array}$} & \multirow[b]{2}{*}{$\begin{array}{l}\text { Corresponding } \\
\text { efficacy }\end{array}$} & \multicolumn{3}{|c|}{$0.7 \%$ dataset } & \multicolumn{3}{|c|}{$0.5 \%$ dataset } & \multicolumn{3}{|c|}{$0.3 \%$ dataset } \\
\hline & & $\begin{array}{c}\text { Number of } \\
\text { assigned } \\
\text { plants }\end{array}$ & $\begin{array}{l}\text { Correct } \\
\text { prediction }\end{array}$ & $\begin{array}{c}\text { True } \\
\text { positive } \\
\text { rate }\end{array}$ & $\begin{array}{c}\text { Number of } \\
\text { assigned } \\
\text { plants }\end{array}$ & $\begin{array}{c}\text { Correct } \\
\text { prediction }\end{array}$ & $\begin{array}{c}\text { True } \\
\text { positive } \\
\text { rate }\end{array}$ & $\begin{array}{c}\text { Number of } \\
\text { assigned } \\
\text { plants }\end{array}$ & $\begin{array}{l}\text { Correct } \\
\text { prediction }\end{array}$ & $\begin{array}{c}\text { True } \\
\text { positive } \\
\text { rate }\end{array}$ \\
\hline D1 & E7 & 26 & 22 & 0.85 & 24 & 20 & 0.83 & 24 & 20 & 0.83 \\
\hline D2 & E7 & 1 & 1 & 1.00 & 5 & 5 & 1.00 & 1 & 1 & 1.00 \\
\hline \multirow{2}{*}{ D3 } & $\mathrm{E} 4$ & \multirow{2}{*}{42} & 42 & 1.00 & \multirow{2}{*}{33} & 33 & 1.00 & \multirow{2}{*}{28} & 28 & 1.00 \\
\hline & E7 & & 38 & 0.90 & & 30 & 0.91 & & 25 & 0.89 \\
\hline D4 & E7 & 0 & 0 & - & 0 & 0 & - & 0 & 0 & - \\
\hline D5 & E7 & 0 & 0 & - & 0 & 0 & - & 0 & 0 & - \\
\hline D6 & E5 & 38 & 38 & 1.00 & 37 & 37 & 1.00 & 32 & 32 & 1.00 \\
\hline D7 & E7 & 0 & 0 & - & 0 & 0 & - & 0 & 0 & - \\
\hline D8 & E7 & 10 & 8 & 0.80 & 8 & 7 & 0.88 & 6 & 5 & 0.83 \\
\hline D9 & E7 & 0 & 0 & - & 0 & 0 & - & 1 & 1 & 1.00 \\
\hline D10 & E6 & 6 & 4 & 0.67 & 2 & 0 & - & 3 & 1 & 0.33 \\
\hline D11 & E6 & 65 & 65 & 1.00 & 71 & 71 & 1.00 & 60 & 60 & 1.00 \\
\hline D12 & E7 & 0 & 0 & - & 0 & 0 & - & 0 & 0 & - \\
\hline D13 & E7 & 0 & 0 & - & 0 & 0 & - & 5 & 5 & 1.00 \\
\hline \multirow{2}{*}{ D14 } & $\mathrm{E} 2$ & \multirow{2}{*}{54} & 44 & 0.81 & \multirow{2}{*}{45} & 36 & 0.80 & \multirow{2}{*}{35} & 26 & 0.74 \\
\hline & $\mathrm{E} 4$ & & 54 & 1.00 & & 45 & 1.00 & & 35 & 1.00 \\
\hline \multirow{2}{*}{ D15 } & E7 & \multirow{2}{*}{38} & 37 & 0.97 & \multirow{2}{*}{34} & 34 & 1.00 & \multirow{2}{*}{33} & 33 & 1.00 \\
\hline & E8 & & 31 & 0.82 & & 30 & 0.88 & & 29 & 0.88 \\
\hline D16 & E9 & 32 & 31 & 0.97 & 32 & 32 & 1.00 & 27 & 27 & 1.00 \\
\hline D17 & E1 & 13 & 13 & 1.00 & 9 & 9 & 1.00 & 8 & 8 & 1.00 \\
\hline D18 & E3 & 0 & 0 & - & 5 & 5 & 1.00 & 4 & 4 & 1.00 \\
\hline \multicolumn{2}{|c|}{ Total assigned plants } & & 135 & & & 129 & & & 117 & \\
\hline
\end{tabular}

lower coverage of disease classes. The number of Jamu pairs, that is, the number of edges in the network, affect the number of DPClusO resulting clusters and number of Jamu formulas per cluster. As a consequence, for the larger dataset networks, the success rate becomes lower and the coverage of disease classes is lower but prediction of more plant-disease relations can be achieved.

\section{Conclusions}

This paper introduces a novel method called supervised clustering for analyzing big biological data by integrating network clustering and selection of clusters based on supervised learning. In the present work we applied the method for data mining of Jamu formulas accumulated in KNApSAcK database. Jamu networks were constructed based on correlation similarities between Jamu formulas and then network clustering algorithm DPClusO was applied to generate high density Jamu modules. For the analysis of the next steps potential clusters were selected by supervised learning. The successful clusters containing several Jamu related to the same disease might be useful for finding main ingredient plant for that disease and the lower matching score value clusters will be associated with varying plants which might be supporting ingredients. By applying the proposed method important plants from Jamu formulas for every classes of disease were determined. The plant to disease relations predicted by proposed network based method were evaluated in the context of previously published results and were found to produce a TPR of $90 \%$. For the larger dataset networks, success rate and the coverage of disease classes become lower but prediction of more plant-disease relations can be achieved.

\section{Conflict of Interests}

The authors declare that there is no financial interest or conflict of interests regarding the publication of this paper.

\section{Acknowledgments}

This work was supported by the National Bioscience Database Center in Japan and the Ministry of Education, Culture, Sports, Science, and Technology of Japan (Grant-in-Aid for Scientific Research on Innovation Areas "Biosynthetic Machinery. Deciphering and Regulating the System for Creating Structural Diversity of Bioactivity Metabolites (2007)”). 


\section{References}

[1] R. Verporte, H. K. Kim, and Y. H. Choi, "Plants as source of medicines," in Medicinal and Aromatic Plants, R. J. Boger, L. E. Craker, and D. Lange, Eds., chapter 19, pp. 261-273, 2006.

[2] A. Furnharm, "Why do people choose and use complementary therapies?" in Complementary Medicine: An Objective Appraisal, E. Ernst, Ed., pp. 71-88, Butterworth-Heinemann, Oxford, UK, 1996.

[3] E. Ernst, "Herbal medicines put into context," British Medical Journal, vol. 327, no. 7420, pp. 881-882, 2003.

[4] F. M. Afendi, T. Okada, M. Yamazaki et al., "KNApSAcK family databases: integrated metabolite-plant species databases for multifaceted plant research," Plant and Cell Physiology, vol. 53, no. 2, p. el, 2012.

[5] F. M. Afendi, N. Ono, Y. Nakamura et al., "Data mining methods for omics and knowledge of crude medicinal plants toward big data biology," Computational and Structural Biotechnology Journal, vol. 4, no. 5, Article ID e201301010, 2013.

[6] F. M. Afendi, L. K. Darusman, A. Hirai et al., "System biology approach for elucidating the relationship between Indonesian herbal plants and the efficacy of Jamu," in Proceedings of the 10th IEEE International Conference on Data Mining Workshops (ICDMW '10), pp. 661-668, Sydney, Australia, December 2010.

[7] F. M. Afendi, L. K. Darusman, A. H. Morita et al., "Efficacy of Jamu formulations by PLS modeling," Current Computer-Aided Drug Design, vol. 9, pp. 46-59, 2013.

[8] F. M. Afendi, L. K. Darusman, M. Fukuyama, M. Altaf-UlAmin, and S. Kanaya, "A bootstrapping approach for investigating the consistency of assignment of plants to Jamu efficacy by PLS-DA model," Malaysian Journal of Mathematical Sciences, vol. 6, no. 2, pp. 147-164, 2012.

[9] W. Winterbach, P. V. Mieghem, M. Reinders, H. Wang, and D. de Ridder, “Topology of molecular interaction networks," BMC Systems Biology, vol. 7, article 90, 2013.

[10] C. Bachmaier, U. Brandes, and F. Schreiber, "Biological network," in Handbook of Graph Drawing and Visualization, pp. 621-651, CRC Press, 2013.

[11] X. Chen, M. Chen, and K. Ning, "BNArray: an R package for constructing gene regulatory networks from microarray data by using Bayesian network," Bioinformatics, vol. 22, no. 23, pp. 2952-2954, 2006.

[12] P. Langfelder and S. Horvath, "WGCNA: an R package for weighted correlation network analysis," BMC Bioinformatics, vol. 9, article 559, 2008.

[13] A. Martin, M. E. Ochagavia, L. C. Rabasa, J. Miranda, J. Fernandez-de-Cossio, and R. Bringas, "BisoGenet: a new tool for gene network building, visualization and analysis," $B M C$ Bioinformatics, vol. 11, article 91, 2010.

[14] M. Altaf-Ul-Amin, M. Wada, and S. Kanaya, "Partitioning a PPI network into overlapping modules constrained by highdensity and periphery tracking," ISRN Biomathematics, vol. 2012, Article ID 726429, 11 pages, 2012.

[15] M. Altaf-Ul-Amin, H. Tsuji, K. Kurokawa, H. Asahi, Y. Shinbo, and S. Kanaya, "DPClus: a density-periphery based graph clustering software mainly focused on detection of protein complexes in interaction networks," Journal of Computer Aided Chemistry, vol. 7, pp. 150-156, 2006.

[16] S. K. Kachigan, Multivariate Statistical Analysis: A Conceptual Introduction, Radius Press, New York, NY, USA, 1991.
[17] J. L. Rodgers and W. A. Nicewander, "Thirteen ways to look at the correlations coefficient," The American Statiscian, vol. 42, pp. 59-66, 1995.

[18] M. Li, J.-E. Chen, J.-X. Wang, B. Hu, and G. Chen, "Modifying the DPClus algorithm for identifying protein complexes based on new topological structures," BMC Bioinformatics, vol. 9, article 398, 2008.

[19] World Health Organization, "International Classification of Diseases (ICD) 10," 2010, http://www.who.int/classifications/ icd/en/.

[20] National Center for Biotechnology Information, Genes and Disease, NCBI, Bethesda, Md, USA, 1998.

[21] P. Erdos and A. Renyi, "On the evolution of random graph," Publicationes Mathematicae Debrecen, vol. 6, pp. 290-297, 1959.

[22] A.-L. Barabási and R. Albert, "Emergence of scaling in random networks," Science, vol. 286, no. 5439, pp. 509-512, 1999.

[23] A. Vázquez, "Growing network with local rules: preferential attachment, clustering hierarchy, and degree correlations," Physical Review E-Statistical, Nonlinear, and Soft Matter Physics, vol. 67, no. 5, Article ID 056104, 15 pages, 2003.

[24] Max Planck Institut Informatik, "NetworkAnalyzer," 2013, http://med.bioinf.mpi-inf.mpg.de/netanalyzer/index.php. 

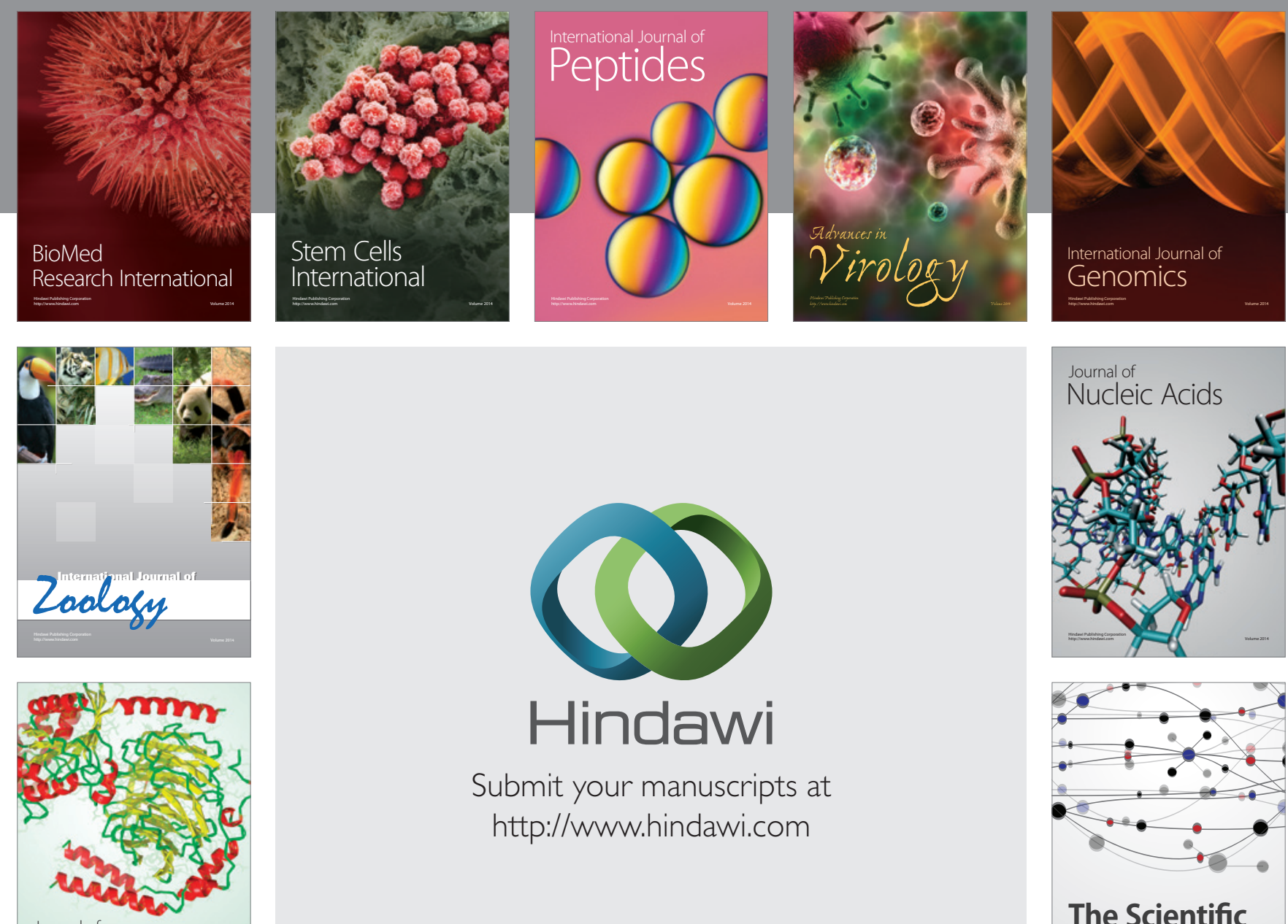

Submit your manuscripts at

http://www.hindawi.com

Journal of
Signal Transduction
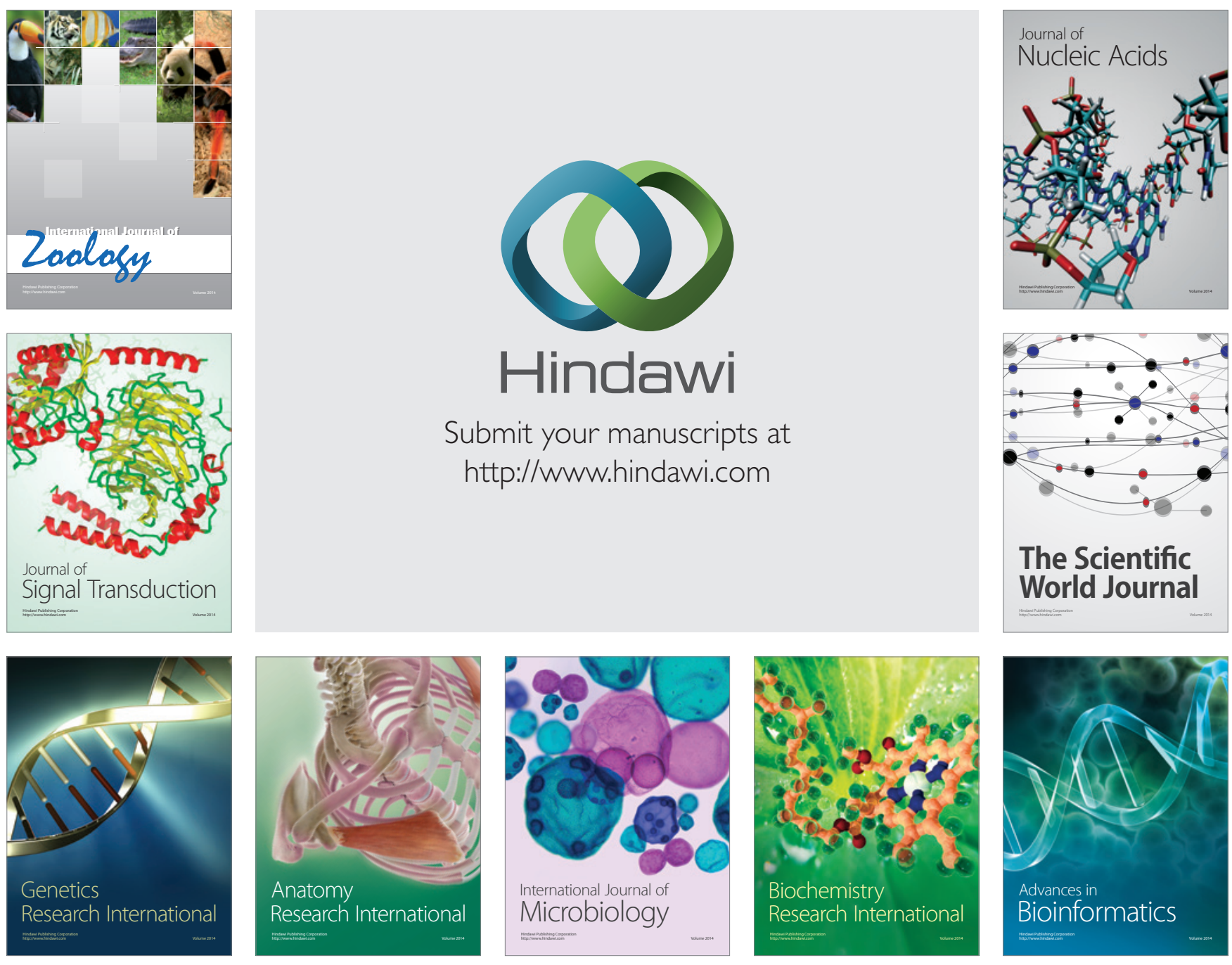

The Scientific World Journal
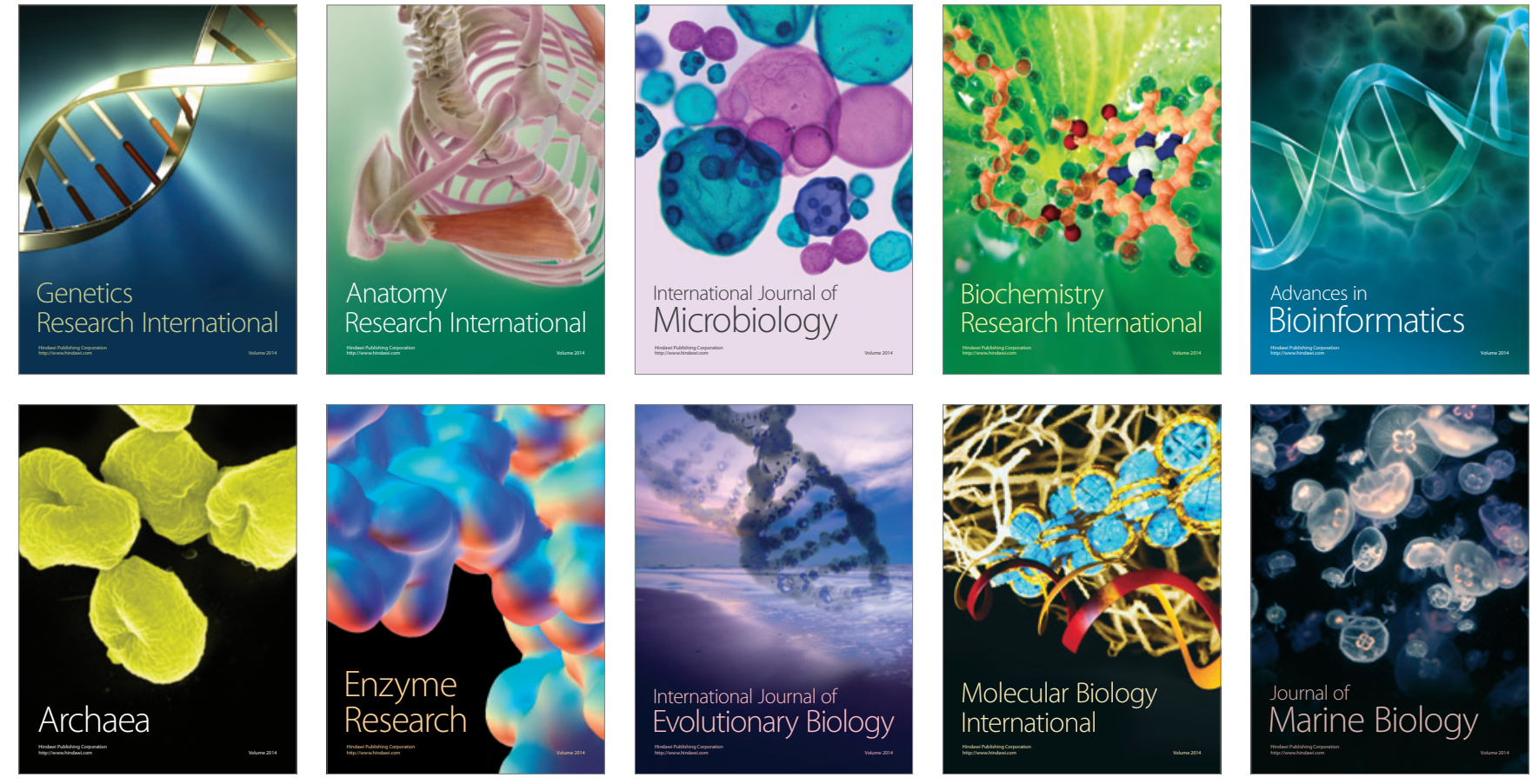